\title{
AGE RELATED OXIDATIVE PROCESSES AND ENDOGENOUS INTOXICATION DYNAMICS OF RATS ARTER TOBACCO SMOKE AFFECTION
}

\author{
P. G. Lyhatskyy, O. B. Rytsyk, L. S. Fira, O. Z. Yaremchuk \\ I. HORBACHEVSKY TERNOPIL STATE MEDICAL UNIVERSITY, TERNOPIL, UKRAINE
}

Background. In an experiment on rats in the content of reactive oxygen species and lipid peroxidation products in blood and liver of rats of different age groups after 45-day affection with tobacco smoke was studied.

Objective. The study was aimed to investigate the rate of reactive oxygen species formation, especially the processes of lipid peroxidation and degree of endogenous intoxication in rats of different age groups in terms of 45 day affection with tobacco smoke.

Methods. The content of ROS was determined in blood neutrophils method gradient centrifugation, the activity of free radical processes in rats evaluated the content of TBA - active products (TBA - AP), the degree of endogenous intoxication - the content average molecular weight (AMW) of the two factions - MW1 (dominated by chain amino acids) and MW2 (dominated by aromatic amino acids). Blood, blood serum and liver of the experimental rats were used for the investigation. It was prepared 10\% homogenate in saline from liver tissue.

Results. We have noticed that the destruction of rats by tobacco smoke for 45 days caused the increase of ROS in blood content, which is the result of toxic effect on the body. The immature rats were the most sensitive to the affection, which ROS contents in neutrophils increased in 2.75 times till the end of the experiment, in the mature animals it was in 1.65 times higher than in the intacts, in the senile it was higher in 2.43 times than normal rate. It was found that the level of oxygen metabolites and TBA-active products increased during the experiment (on the $15^{\text {th }}, 30^{\text {th }}$ and $45^{\text {th }}$ day of toxicity).

Conclusions. The most pronounced changes were inherent for the immature rats. Accumulation of active toxic metabolites was conducted with endogenous intoxication intensifying that was proved by the high content of catabolism products in the body - middle mass molecules that are likely to grow in serum of rats of all age groups.

KEY WORDS: oxidative processes, lipid peroxidation, reactive oxygen species, endogenous intoxication, tobacco smoke, rats.

\section{Introduction}

At present tobacco smoke is one of the most common anthropogenic agents that has a wide range of effects on morphofunctional status of various systems of the body $[8,10,15,16]$. The share of tobacco smoke in the overall air pollution is quite considerable and each year continues to rise, so it is one of powerful polluters of the environment. It is established that the basis of the pathogenic action of contaminated pollutants or cigarette smoke air is the oxidant aggression on the mucosa of

Corresponding author: Petro Lyhatskyy, Department of Medical Biochemistry, I. Horbachevsky Ternopil State Medical University, 1 Maidan Voli, Ternopil, Ukraine, 46001

Phone number: +380352254784

E-mail: luhatsky@tdmu.edu.ua respiratory tract reactive oxygen species, nitrogen dioxide and sulfur and other free radicals, which cause the activation of lipid peroxidation and damage of biological membranes $[3,11]$. Smoking generates the reactive oxygen species (ROS: $\mathrm{O}_{2} \doteqdot \mathrm{O}_{2}{ }^{1}, \mathrm{OH}, \mathrm{H}_{2} \mathrm{O}_{2}$, etc.), which are important for many physiological and biochemical processes: the regulation of vascular tone, cell proliferation, prostaglandins synthesis, signals transmission from intercellular signalling molecules of regulatory system that control the expression of phagocytes genes antimicrobial action $[6,9,14]$. Under the influence of extreme factors of various origin (chemical contamination, ionizing radiation, hyper- and hypoxia, toxic substances, inflammatory processes) formation of ROS in organisms is enhanced [12, 
$13,17,18]$. The last causes free radical oxidation activation that leads to increased lipid peroxidation (LPO), oxidative modification of proteins (OMP), degradation of nucleic acids, carbohydrates, increasing of endogenous intoxication in the organism.

However, in literature there is no definitive data on the rate of formation of ROS and processes of lipid peroxidation activation in rats of different ages after prolonged exposure with tobacco smoke.

Accordingly, the study was aimed to investigate the rate of reactive oxygen species formation, especially the processes of lipid peroxidation and degree of endogenous intoxication in rats of different age groups in terms of 45-day affection with tobacco smoke.

\section{Material and Methods}

The experiments were conducted on white outbred male rats, which were kept on a vivarium standard diet of Ternopil State Medical University. The rats were divided into three age groups: the first - immature, weight $60-80 \mathrm{~g}$, the second - mature, weight $180-200 \mathrm{~g}$ and the third - senile, weight 300-320 g. Each age group consisted of two subgroups: an intact control (C) and an experimental group (E). The rats of the experimental groups were affected with tobacco smoke during 45 days. The model of the chronic smoke was created by means of airtight chamber volume of 30 litres that allowed animals to fumigate free behaviour. Tobacco smoke was formed by smoking of 6 cigarettes Prima sribna (synia) ( $0.6 \mathrm{mg}$ of nicotine and $8 \mathrm{mg}$ of tar), was served into it through openings in the chamber. Six animals were simultaneously in the chamber during 6 minutes. The animals of the control group were also 6 minutes in a sealed chamber, but were not subjected to smoke.

In 15,30 and 45 days after the beginning of the affecting the animals with tobacco smoke, they were taken out of the experiment by euthanasia, which was performed with thiopental anaesthesia.
Blood, blood serum and liver of the experimental rats were used for investigation. 10\% homogenate in saline of liver tissue was prepared.

The content of ROS was determined by blood neutrophils method [6], the activity of free radical processes in rats evaluated the content of TBA-active products (TBA-AP) [5], the degree of endogenous intoxication - the average molecular weight (AMW) content of two factions [2, 7]: $\mathrm{MW}_{1}$ (dominated by chain amino acids) and $\mathrm{MW}_{2}$ (dominated by aromatic amino acids).

We followed general principles of animal experiments in the research that were approved at the National Congress on Bioethics (Kyiv, Ukraine, 2001) and consistent with the provisions of the European Convention for the Protection of vertebrate animals used for experimental and other scientific purposes (Strasbourg, France, 1985) [4]. Parametric (according to Student) and non-parametric (according to Wilcoxon) methods for data statistical analysis were used. Changes were considered as significant at $p \leq 0.05$.

\section{Results and Discussion}

Any stress reaction normally is accompanied by a brief increase in the number of ROS [6]. This is due to adaptation to extreme conditions in which ROS play a role of a secondary messenger participating in signal transduction and activation of transcription factors and related genes, including those encoding enzymes antioxidants.

We noticed that the affection of the rats by tobacco smoke during 45 days caused the increase of ROS in blood content (Table 1), which is the result of toxic factor on the body. The immature rats were the most sensitive to the affection, the ROS contents in neutrophils increased in 2.75 times at the end of the experiment, in the mature animals it was in 1.65 times higher than in the intacts, in the senile it was in 2.43 times higher than normal rate.

It is established that under the influence of various extreme factors (chemical contami-

Table 1. The contents of ROS (\%) in blood neutrophils of the rats affected with tobacco smoke of all ages ( $M \pm m ; n=72)$

\begin{tabular}{|l|c|c|c|}
\hline \multirow{2}{*}{$\begin{array}{c}\text { Research time, } \\
\text { days }\end{array}$} & \multicolumn{3}{c|}{ Groups of the experimental animals } \\
\cline { 2 - 4 } & immature rats & mature rats & senile rats \\
\hline intact rats & $15.06 \pm 0.71$ & $18.47 \pm 0.22$ & $19.87 \pm 0.86$ \\
\hline $15^{\text {th }}$ day of the affection & $17.19 \pm 0.83$ & $28.58 \pm 2.53^{*}$ & $25.38 \pm 1.95$ \\
\hline $30^{\text {th }}$ day of the affection & $39.25 \pm 1.29 *$ & $29.54 \pm 0.50 *$ & $41.89 \pm 0.78^{*}$ \\
\hline $45^{\text {th }}$ day of the affection & $41.52 \pm 2.37 *$ & $30.63 \pm 0.66 *$ & $48.32 \pm 0.57 *$ \\
\hline
\end{tabular}

Note: * - differences between the intact rats and the rats affected with tobacco smoke $(p \leq 0.05)$. 
nation, ionizing radiation, hyper- and hypoxia, toxic substances, inflammatory processes) the formation of ROS in organisms is enhanced. Among the reasons that causes of the increased production of ROS are: violation of electron transport in the respiratory chain of mitochondria and electron transport chain microsomes, the intensification of synthesis and oxidation of catecholamines, the increased degradation adenylate nucleotides and activation of xanthine oxidase, the emergence of a pool of catalytically active metal ions of variable valence (especially $\mathrm{Fe}^{2+}$ ), the synthesis of prostaglandins from arachidonic acid (reactions catalysed cyclooxygenase and lipoxygenase), the activation of inducible form of nitric oxide synthase, the increased activity of phagocytes [14].

The intensification of free radical oxidation reactions is one of the manifestations of oxygen metabolites toxic effects. Free radical oxidation is a universal mechanism, which controls the most important homeostatic physical and chemical parameters of cells: strength, integrity and selective permeability of cell membranes [3].

A significant increase of ROS, which was evidenced after poisoning the animals with tobacco smoke, caused the intensification of free radical oxidation including lipid peroxidation. As one of the indicators of lipid peroxidation, the contents of TBA-AP significantly increased in serum and liver of the rats after tobacco smoke intoxication (Table 2). In serum of the immature animals on the $15^{\text {th }}$ day of the intoxication, this indicator increased by $30 \%$ (changes were not significant). The other age groups in this period were more sensitive: the TBA-AP content in serum increased by $87 \%$ in the mature animals and by $58 \%$ in the senile $(p \leq 0.05)$.

The intoxication with tobacco smoke during 45 days caused the significant activation of lipid peroxidation, which was evidenced by considerable increase of TBA-AP content in serum of the animals of all experimental groups (in the immature rats the indicator increased in 2 times, in the immature - in 2.1 times, in the senile - in 1.8 times).

In liver of the experimental animals a similar increase of investigational product lipid peroxidation was observed during the experiment. By the end of tobacco smoke toxicity (on the $45^{\text {th }}$ day of the research), the increase of TBA-AP content in liver of the mature and senile animals in 1.8 times respectively was evidenced. The immature animals were more sensitive to this indicator and the content of intermediate peroxidation increased in 3.2 times in the test organ. Perhaps this is due to insufficient decontaminating of liver, including oxidation processes and microsomal enzymes that took part in it. In pathological processes the average molecular weight (AMW) is quite important, some its fraction exhibit high biological activity [1]. The spectrum of pathological action of these compounds has a different character: they break the physical and chemical properties of cell membranes, inhibit tissue respiration and oxidative phosphorylation, inhibit ATP activity and DNA synthesis, activate lipid peroxidation and reduce the activity of antioxidant defence cells, stimulate cellular proliferation and inhibiting the process of apoptosis [2]. AMW accumulation is a consequence of the activation of catabolic processes and reduction of liver detoxification function. Metabolic syndrome intoxication is developing, which leads to severe functional impairment and morphological damage to various organs and systems. Activation of ROS-formation processes and lipid peroxidation causes increased proteolysis reactions in the body affected with tobacco smoke, accompanied by accumulation

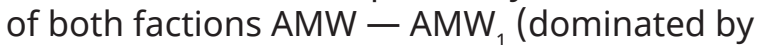
chain amino acids) and $\mathrm{AMW}_{2}$ (dominated by aromatic amino acids). The results of the

Table 2. The content of TBA-AP in blood serum $(\mathrm{mmol} / \mathrm{L})$ and liver $(\mathrm{mmol} / \mathrm{kg})$ of the rats in dynamics of tobacco smoke affection $(M \pm m ; n=72)$

\begin{tabular}{|c|c|c|c|}
\hline \multirow{2}{*}{$\begin{array}{c}\text { Research time, } \\
\text { days }\end{array}$} & \multicolumn{3}{|c|}{ Groups of the experimental animals } \\
\hline & immature rats & mature rats & senile rats \\
\hline & \multicolumn{3}{|c|}{ blood serum } \\
\hline Intact rats & $3.28 \pm 0.23$ & $1.85 \pm 0.14$ & $2.35 \pm 0.14$ \\
\hline $15^{\text {th }}$ day of the affection & $4.28 \pm 0.31$ & $3.47 \pm 0.29 *$ & $3.71 \pm 0.28$ * \\
\hline $30^{\text {th }}$ day of the affection & $4.85 \pm 0.36 *$ & $4.28 \pm 0.31 *$ & $4.42 \pm 0.28$ * \\
\hline \multirow[t]{2}{*}{$45^{\text {th }}$ day of the affection } & $6.62 \pm 0.08 *$ & $3.94 \pm 0.27 *$ & $4.23 \pm 0.17 *$ \\
\hline & \multicolumn{3}{|c|}{ Liver } \\
\hline Intact rats & $15.49 \pm 1.28$ & $14.42 \pm 0.71$ & $16.55 \pm 0.98$ \\
\hline $15^{\text {th }}$ day of the affection & $18.69 \pm 1.28$ & $23.50 \pm 1.35 *$ & $25.12 \pm 2.09 *$ \\
\hline $30^{\text {th }}$ day of the affection & $30.86 \pm 1.55 *$ & $28.73 \pm 0.78 *$ & $29.06 \pm 1.46 *$ \\
\hline $45^{\text {th }}$ day of the affection & $49.66 \pm 3.38 *$ & $26.49 \pm 1.51 *$ & $29.69 \pm 2.39 *$ \\
\hline
\end{tabular}


Table 3. AMW content in blood serum (cu/L) of the rats in dynamics of tobacco smoke affection ( $M \pm m ; n=72)$

\begin{tabular}{|l|c|c|c|}
\hline \multirow{2}{*}{$\begin{array}{c}\text { Research time, } \\
\text { days }\end{array}$} & \multicolumn{3}{|c|}{ Groups of the experimental animals } \\
\cline { 2 - 4 } & immature rats & mature rats & senile rats \\
\hline Intact rats & $14.00 \pm 1.15$ & $11.00 \pm 0.85$ & $13.66 \pm 0.61$ \\
\hline $15^{\text {th }}$ day of the affection & $19.00 \pm 1.52$ & $17.66 \pm 1.20^{*}$ & $18.00 \pm 1.55$ \\
\hline $30^{\text {th }}$ day of the affection & $37.00 \pm 1.12^{*}$ & $31.00 \pm 1.12^{*}$ & $35.66 \pm 0.61^{*}$ \\
\hline $45^{\text {th }}$ day of the affection & $41.66 \pm 0.95^{*}$ & $33.00 \pm 1.52^{*}$ & $38.00 \pm 1.03^{*}$ \\
\hline \multicolumn{3}{|c|}{ AMW $_{2}$} \\
\hline Intact rats & $16.66 \pm 0.84$ & $12.67 \pm 0.84$ & $15.33 \pm 0.67$ \\
\hline $15^{\text {th }}$ day of the affection & $23.00 \pm 2.29$ & $15.33 \pm 0.66$ & $20.33 \pm 1.82$ \\
\hline $30^{\text {th }}$ day of the affection & $28.67 \pm 0.67 *$ & $18.66 \pm 0.67 *$ & $23.33 \pm 0.99 *$ \\
\hline $45^{\text {th }}$ day of the affection & $36.33 \pm 1.20^{*}$ & $21.66 \pm 1.20^{*}$ & $29.66 \pm 1.20$ \\
\hline
\end{tabular}

research of this indicator in blood serum are presented in Table 3.

After 15-day toxicity with tobacco smoke in blood serum of the immature rats the $\mathrm{AMW}_{1}$ content increased by $35 \%, \mathrm{AMW}_{2}-$ by $38 \%$. By the end of the experiment, these indices increased in 3 and 2.2 times respectively in this age group. At the end of the research in the mature rats the $\mathrm{AMW}_{1}$-content in blood serum was in 3 times higher than in the intact animals, $\mathrm{AMW}_{2}$-content was in 1.7 times higher than normal. Similarly, the increased content of MSM in the senile rats in 45 days after the tobacco intoxication in blood serum of this age group the $\mathrm{AMW}_{1}$-content was in 2.8 times higher than the level of the intact control, the $\mathrm{AMW}_{2}$-content exceeded the level of the healthy animals in 1,9 times. Analysing the processes of catabolism in the affected organism we can notice that they were activated in all age groups of rats similarly. Obviously, tissue hypoxia is the primary in the development of destructive processes in the organism after tobacco smoke toxicity due to the breach of oxygen transport.

\section{Conclusions}

Due to the chronic affection with tobacco smoke on the rats of different ages the massive formation of reactive oxygen species in neutrophils causes activation of lipid peroxidation and permanent changes of endogenous intoxication (the increase of TBA-active products in blood serum and liver of the effected rats, the accumulation of average molecular weight). Immature rats were the most sensitive to tobacco smoke; metabolic disorders were the most pronounced as well.

\section{References}

1. Andreychyn SM, Holomasha TM. The current idea of endogenous metabolic intoxication. Infectious diseases 2012; 1 (67): 84-88.

2. Nikolskaya VA, DanylchenkoYuD, Memetova ZN. Biochemical aspects of consideration on the role of middle mass molecules in the body. Scientists'notes of V.I. Vernadsky Taurian National University. Series “Biology, Chemistry" 2013; 26 (65): 139-145.

3. Hryshchuk LA, Marushchak MI. Dynamics of lipid peroxidation and antioxidant protection in rats under acute lung injury. Tuberculosis, pulmonary diseases, HIV infection 2011; 2 (5): 16-20.

4. Doctor's Ethics and Human Rights: regulations on the use of animals in biomedical experiments.
Experimental and clinical physiology and biochemistry 2003; 2 (22): 108-109.

5. Lushchak VI, Bahniukova TV, Lushchak OV. Indicators of oxidative stress. Tiobarbiturativ products and protein carbonyl groups. Ukrainian Biochemistry journal 2004; 26: 136-141.

6. Maruschak MI. Reactive oxygen intermediatesin the development and progression of acute lung injury in an experiment. Med. himiya 2012; 14 (1): 104-108.

7. Nikolaichyk VV, Kirkovskiy VV, Main VM et al. Middle molecules - education and methods for determining. Laboratory case 1989; 8: 31-33.

8. Krasovskyi KS, Andreyeva TI, Hryhorenko AA, Butylska NA. Evaluation of smoking frequency in 
Ukraine. Bulletin of Social Hygiene and Organisation of Health Care of Ukraine 2009; 2: 91-99.

9. Pikas OB.Current level of cigarette smoking its effect on humans diseases incidence. Bukovyna Medical Journal 2015; 4 (76): 227-230.

10. Balakirieva OM, Bondar TV, Halich YuP et al. The frequency and trends in tobacco, alcohol, drug abuse among the youth in Ukraine. O.Yaremenko Ukrainian Instituteof Social Research. K.: OBNOVA 2011; 176.

11. Sakharova HM, Sakharov HM, Antonov AN. Prevention the tobacco epidemic - the preservation of human health. Prevention of diseases and health care. Preventive medicine 2010; 13 (6): 3-7.

12. Tiazhka OV, Vanhanova TO. Passive smoking for toddlers. Transport Health of Ukraine 2012; 1: 93-99.
13. Chuchalin AH. Respiratory diseases and smoking. Therapeutic archive 2009; 3: 5-9.

14. Haussmann $\mathrm{HJ}$ et al. Comparison of fresh and room-aged cigarette sidestream smoke in a subchronic inhalation study on rats. Toxicol Sci 1998; 1: 100-116.

15. Domagala-Kulawik J. Effects of cigarette smoke on the lung and systemic immunity. J Physiol Pharmacol 2008; 6: 19-34.

16. Wirth N [et al]. Respiratory diseases related to passive smoking. Rev Mal Respir 2009; 6: 667-678.

17. Wipfli $\mathrm{H}$ [et al]. Secondhand smoke exposure among women and children: evidence from 31 countries. Am J Public Health 2008; 4: 672-679.

18. Wipfli H, Samet JM. Global economic and health benefits of tobacco control: part 1. Clin Pharmacol Ther 2009; 3: 263-271. 